\title{
Structure-Control of Amphoteric Polyacrylamide and Its Performance as Dry Strength Resin
}

\section{Hideo Baraki*2}

Paper Chemical Business Division, Seiko PMC Co., Ltd. ${ }^{* 1}$

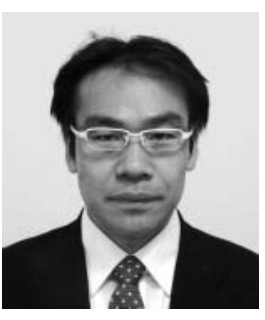

\begin{abstract}
Dry strength resin is known as multifunctional chemicals to enhance paper/paperboard strength, drainage and retention. Especially, polyacrylamide (PAM) based dry strength resin is widely used in various paper/paperboard grades in Japan. Linear, Low-branched, and high-branched PAM containing both anionic and cationic groups were obtained with free radical polymerization. Molecular weight and structure of PAM were determined by gel permeation chromatography coupled on line to a multi-angle laser light scattering detector (GPCMALS). The higher degree of branching, the more compact a polymer chain, which leads to decrease in the viscosity of aqueous solution.

The effects of structure and molecular weight of amphoteric PAM on the performance of dry strength resin were investigated. The high-branched PAM with higher molecular weight showed greater performance in retention of PAM and paper strength. The zeta-potential of amphoteric PAM increased with the increasing of the degree of branching. The high-branched amphoteric PAM was able to form polyionic complexes in high salt concentration (electro conductivity, $650 \mathrm{mS} / \mathrm{m}$ ). The effective iconicity of amphoteric PAM could be controlled by changing the structure of polymer.
\end{abstract}

Keywords : Polyacrylamide, High-branched, Structure Control, Polyionic Complex, Paper Strength, Drainage

\section{Introduction}

Amphoteric polyacrylamide (amphoteric PAM) is commonly used in paper and paperboard manufacturing to improve not only dry strength but also runnability of paper machine in many ways like better drainage and dewatering, higher retention of wet end additives, like sizing agent, and fillers like calcium carbonate. Dry strength resin clas-

\footnotetext{
${ }^{*} 3$-37 Ohnodai, 2-chome, Midori-ku, Chiba-city, Chiba, 267-0056, Japan

*2E-mail : hideo-baraki@seikopmc.co.jp
}

sified as amphoteric PAM is made by co-polymerizing acrylamide, a main component, with other kinds of monomers such as anionic monomer, cationic monomer and functional monomer, and is supplied to customers in aqueous solution.

PAM of higher molecular weight is more retained on pulp fiber ${ }^{1)}$, and improves dry strength. The solution of high-molecular-weight PAM, however, gets very viscous, causes troubles in shipping and handling, and practically is not acceptable. Moreover, too much coagulation on fiber disturbs sheet formation, which results in poor dry strength. To cope with those problems, PAM has to be po- 
lymerized to a large molecule without increasing the viscosity of its aqueous solution by restraining the spread of its molecular chain. So, PAM that is branched in its molecule (branched PAM) has been developed ${ }^{2-4)}$.

Branched PAM can be structured to poly-ionic complexes, a kind of pseudo-macromolecule, which is formed by the interaction of electrostatic force, by controlling positions of ionic groups in its molecule. Several studies are going on to improve drainage by forming branched PAM to poly-ionic complex ${ }^{5,6}$. But recent trends like followings are unfavorable for using wet end chemicals. Recycled pulp is used in a larger and larger ratio, paper machines are becoming larger and running faster, and electro-conductivity of water is increasing due to closed water loop in wet end. So, amphoteric PAM that could be effective in such severe conditions is wanted.

We investigated on improving effectiveness of amphoteric PAM by focusing on its structural parameters such as the radius of gyration, molecular weight and the degree of branching.

\section{Experiment}

\section{1 Amphoteric PAM}

Six kinds of amphoteric PAMs were synthesized by radical polymerization, using itaconic acid as an anionic monomer and $N$. $N$-dimethylaminoethylmetacrylate as a cationic monomer. Their ionic monomer contents are the same though they had different molecular weight, structure and radius of gyration. Their characteristics are summarized in Table 1.

\subsection{Determination by GPC-MALS}

Gel permeation chromatography (Prominence UFLC by Shimadzu Corporation) was coupled on line to an intensity detector (RI-101 by Shodex Co.) and also to a multi-angle laser light scattering detector (DAWN EOS by Wyatt Technology Co.).

\subsection{Viscosity measurement}

Viscosity was measured by Brookfield viscometer (TVB-10 by Toki Sangyou Co.) equipped with M 4 rotor at $25^{\circ} \mathrm{C}$. The revolution of the rotor was selected based on specimen's viscosity.

\section{4 Intrinsic viscosity}

An amphoteric PAM sample was diluted with $4 \%$ sodium chloride solution to a pre-determined consistency. Using capillary viscometer of Ubbelohde type, its flow down time was measured at $25^{\circ} \mathrm{C}$. After making a Huggins plot $^{7)}$ with measured specific viscosities $\eta_{\text {sp }}$, its intrinsic viscosity $[\eta]$ was calculated.

\subsection{Light transparency of diluted Amphoteric PAM}

Using ion-exchanged water of which electric conductivity was adjusted to $150 \mathrm{mS} / \mathrm{M}$ with $\mathrm{CaSO}_{4} \cdot 2 \mathrm{H}_{2} \mathrm{O}, 0.1 \%$ amphoteric PAM solution was prepared. After adjusting its $\mathrm{pH}$ to 3 with $0.05 \mathrm{~N}$ sulfuric acid, a sample solution was set to an automatic titrator equipped with $\mathrm{pH}$ electrode and light intensity detector $(620 \mathrm{~nm})$. Titration was carried out with sodium hydroxide solution of $0.1 \mathrm{~N}$ to follow changes of $\mathrm{pH}$ and light intensity. Another solution was also prepared of which electric conductivity was adjusted to $650 \mathrm{mS} / \mathrm{m}$ by adding $\mathrm{CaCl}_{2} \cdot 2 \mathrm{H}_{2} \mathrm{O}$ to the former solution of which electro-conductivity was $150 \mathrm{mS} / \mathrm{m}$. Titration was done in the same way as before.

\section{6 Handsheet preparation}

Waste corrugated board was refined to 350 Canadian Standard Freeness. Its pulp consistency was adjusted to $2.4 \%$ and its electric conductivity was controlled to 150 $\mathrm{mS} / \mathrm{m}$. Under stirring, aluminum sulfate and then amphoteric PAM solution ( $1.2 \%$ consistency) were added. The dosage of aluminum sulfate was $1 \%$ per pulp, and that of amphoteric PAM was $1 \%$ per pulp for samples I VI. Handsheets were prepared under the $\mathrm{pH}$ of 7 . Drainage was evaluated by dynamic drainage jar. Pulp slurry was prepared in the same way by adding chemicals, and drain-

Table 1 Characterization of amphoteric PAM

\begin{tabular}{ccccccc}
\hline Sample & Mw $\times 10^{\text {4a) }}$ & Mw/Mn & $\begin{array}{c}\mathrm{Rg}^{\mathrm{a})} \\
(\mathrm{nm})\end{array}$ & $\begin{array}{c}{[\eta]^{\mathrm{b})}} \\
(\mathrm{dL} / \mathrm{g})\end{array}$ & $\begin{array}{c}\text { Viscosity }^{\mathrm{c})} \\
(\mathrm{mPa} \cdot \mathrm{s})\end{array}$ & Structure $^{\mathrm{a})}$ \\
\hline I & 260 & 2.8 & 55 & 1.5 & 7,000 & Low-branched \\
II & 380 & 3.9 & 65 & 2.0 & 18,000 & Low-branched \\
III & 590 & 4.1 & 76 & 2.6 & 73,000 & Low-branched \\
IV & 280 & 3.0 & 67 & 3.5 & $50,000^{\mathrm{d})}$ & Linear \\
V & 330 & 2.9 & 55 & 1.2 & 3,500 & High-branched \\
VI & 560 & 4.2 & 64 & 1.9 & 7,000 & High-branched \\
\hline
\end{tabular}

\footnotetext{
${ }^{a}$ Determined by GPC-MALS

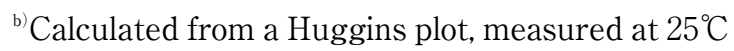

${ }^{c}$ Solution with $20 \%$ polymer, measured at $25^{\circ} \mathrm{C}$

${ }^{d)}$ Solution with $10 \%$ polymer, measured at $25^{\circ} \mathrm{C}$
} 
age time for initial $100 \mathrm{ml}$ drain was measured. Handsheets were conditioned under $23^{\circ} \mathrm{C}$ and $50 \% \mathrm{RH}$ for 24 hours and then their properties were determined.

\subsection{Retention yield of amphoteric PAM}

Nitrogen in handsheet was measured by total nitrogen analyzer by Mitsubishi Chemical Analytic Co. The retention yield of amphoteric PAM was calculated by subtracting nitrogen content in bank sheet, which was prepared without PAM addition, from that of tested sheet.

\section{Result and discussion}

\subsection{Characteristics of amphoteric PAM}

\subsubsection{Structure}

Fig. 1 shows a relationship between the weight-average molecular weight $(\mathrm{Mw})$ measured with GPC-MALS and radius of gyration ( $\mathrm{Rg}$ ). GPC-MALS can give Rg on every molecular weight level, and by analyzing those data, the degree of branching in polymer can be determined ${ }^{8)}$. If two polymers have the same $\mathrm{Rg}$ and are different in molecular weight likeIV, II and VI, one of higher molecular weight is more highly branched than the other. If two polymers have the same molecular weight and are different in the Rg like II and VI, one of less Rg is more highly branched. By analyzing those data, it was found that samples I III had almost the same kind of branched structure. The field in Fig. 1 can be divided to three areas which correspond to three types of molecular structures, linear, low branched and high branched respectively. IV has a linear structure. $\mathrm{I} \sim \mathbb{I}$ have a low branched structure. V $\sim$ VI have a highly branched structure. Fig. 2 illustrates images of those structures in which locations of ionic groups are schematically presented.

\subsubsection{Viscosity of aqueous solution}

Samples IV, II and VI, which had the same degree of Rg

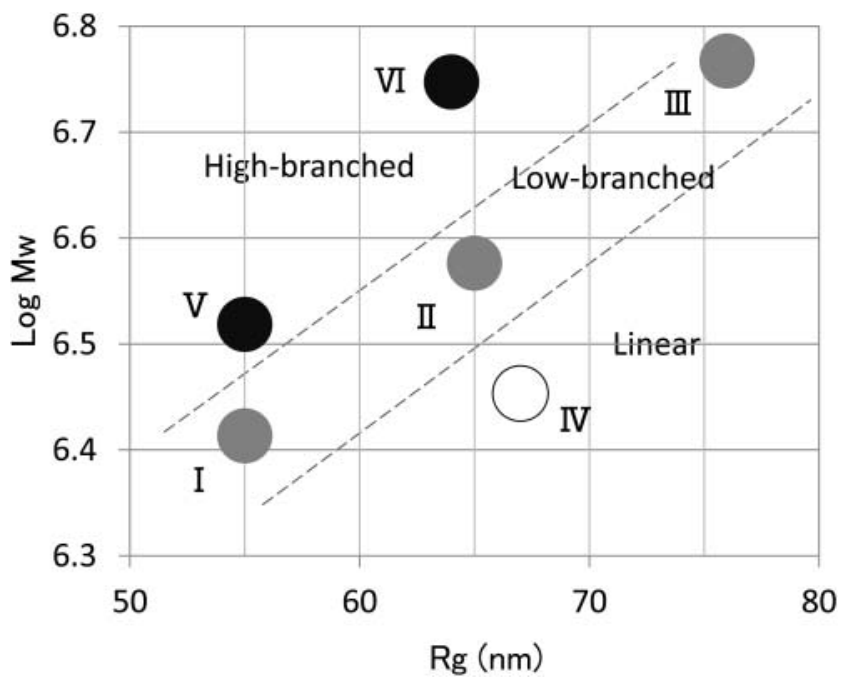

Fig. 1 Molecular weight (Mw) vs radius of gyration (Rg) of amphoteric PAM

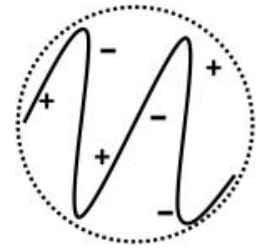

Linear (IV)

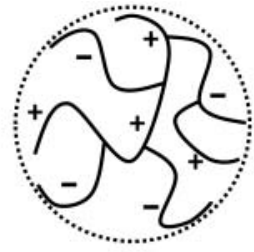

Low-branched (II)

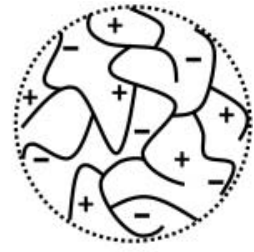

High-branched (VI)
Fig. 2 Schematic illustration of amphoteric PAM

determined by GPC-MALS, were compared with each other in their viscosity of aqueous solution. VI that was of a linear structure had an extremely high viscosity that could not be determined in a normal solid consistency range. When the degree of branching in polymer increased like from I that was of low branch to II that was highly branched, its viscosity went down as listed in Table 1. Amphoteric PAM based dry strength resins sold in the market have physical properties (molecular weight, degree of branching, radius of gyration and viscosity of aqueous solution) similar to those of sample I that was of low branch. Amphoteric PAM like II and III, which has high molecular weight with low degree of branching and which, in other words, has large Rg, has high solution viscosity and is difficult for practical applications. VI that was highly branched had the same level of solution viscosity to that of I . It suggested that by increasing the degree of branching, amphoteric PAM of large Rg could have solution viscosity practically applicable.

3.2 Evaluation of amphoteric PAM as dry strength resin

\subsubsection{Drainage rate test}

The effect on drainage is shown in Table 2 and Fig. 3. By comparing I, II and III with each other, all of which

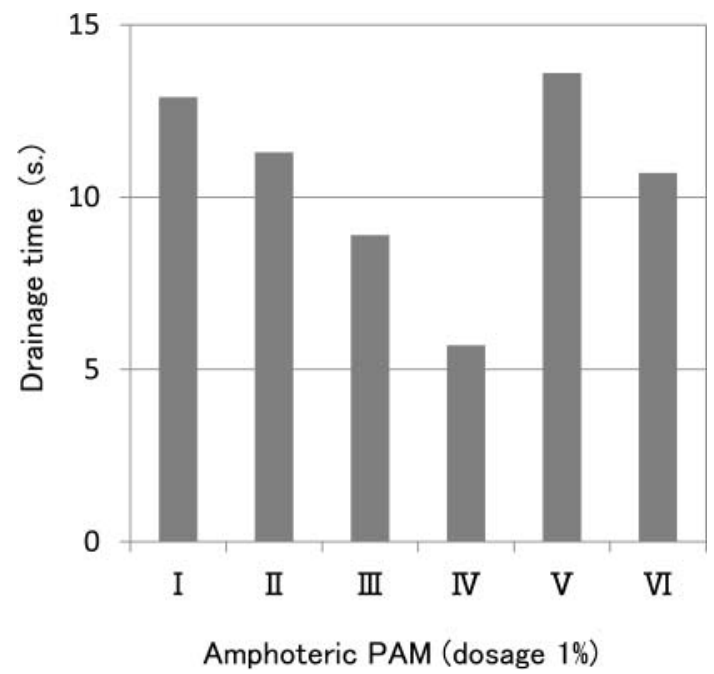

Fig. 3 Effect of amphoteric PAM on drainage time pulp : WCB, electro-conductivity : $150 \mathrm{mS} / \mathrm{m}$, ph : 7. 0 , alum : $1 \%$ 
Table 2 Properties of handsheet and retention of PAM

\begin{tabular}{ccccc}
\hline PAM & $\begin{array}{c}\text { Drainage } \\
(\mathrm{s} .)\end{array}$ & $\begin{array}{c}\text { Dry burst index } \\
\left(\mathrm{kPa} \cdot \mathrm{m}^{2} / \mathrm{g}\right)\end{array}$ & Sheet formation index & $\begin{array}{c}\text { PAM retention } \\
(\%)\end{array}$ \\
\hline I & 12.9 & 3.35 & 88.3 & 44.9 \\
II & 11.3 & 3.39 & 89.7 & 47.3 \\
III & 8.9 & 3.43 & 92.6 & 49.8 \\
IV & 5.7 & 3.34 & 97.5 & 53.8 \\
V & 13.6 & 3.41 & 86.2 & 49.1 \\
VI & 10.7 & 3.55 & 89.3 & 58.9 \\
\hline
\end{tabular}

had a low branched structure, it was found that drainage improved along with larger $\mathrm{Rg}$ though its molecular weight was also larger. The same trend was found with those of high branched structure ( V and VI). When IV, II and VI which had nearly the same Rg were compared each other, IV that was of linear structure was the best and the other two were almost the same level. When they were compared at the same molecular weight basis such as I to IV, II to V and III to VI, ones of low branched or linear structure gave better drainage. The ranking of drainage quality among the samples corresponded to their intrinsic viscosity, neither to their Rg nor to their molecular weight as shown in Table 1 . Intrinsic viscosity represents the volume occupied by a unit weight of polymer in solution as indicated by its unit $\mathrm{dL} / \mathrm{g}$. A higher intrinsic viscosity means that polymer chains entangle each other at a higher level, compared at the same polymer consistency. Therefore, amphoteric PAM of high intrinsic viscosity still maintains entanglement of its polymer chains even after being mixed to pulp slurry and will be able to coagulate pulp and improve drainage.

\subsubsection{Dry strength and retention of amphoteric PAM}

Dry strength of handsheets are summarized in Fig. 4. Among amphoteric PAMs I $\sim$ III which had a similar structure, one that had larger $\mathrm{Rg}$, which was equivalent to higher molecular weight, had better strength. The same trend was observed with V and VI. Among amphoteric PAMs IV, II and VI, which had the same Rg but were different in their molecular weight, one of higher molecular weight that meant more branched had better strength. The same trend was found with I and V. As six amphoteric PAM polymers studied in our experiment had the same ionic composition, they proved that the difference in the polymer structure affected dry burst strength. In general, the strength was dependent on retention yield of amphoteric PAM as shown in Fig. 5. Their retention was improved by increasing molecular weight and degree of branching, and their sheet strength increased accordingly. Polymer IV, which had a linear structure and large Rg,

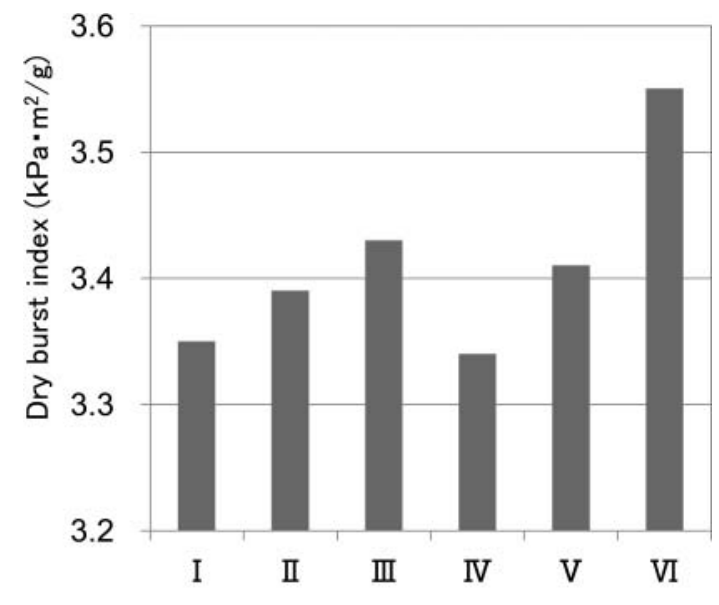

Amphoteric PAM (dosage 1\%)

Fig. 4 Effect of amphoteric PAM on dry burst strength pulp: WCB, electro-conductivity : $150 \mathrm{mS} / \mathrm{m}$, ph : 7. 0 , alum : $1 \%$

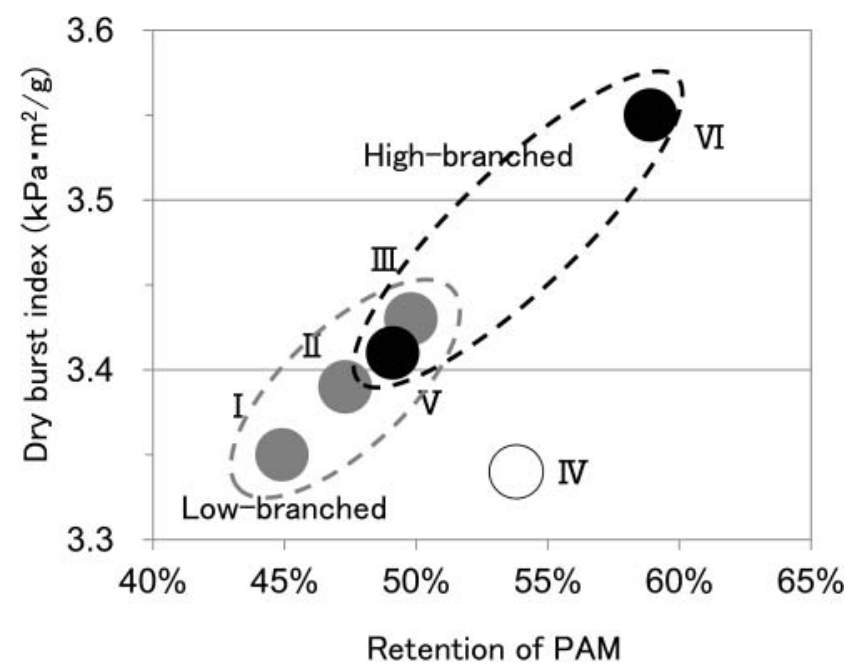

Fig. 5 Plots of Dry burst strength vs retention of amphoteric PAM

could coagulate fiber and fine more than others, and large coagulated flocks of fibers and fines were retained physically in sheet. Though the retention yield of that polymer was high, sheet formation was disturbed by the flocks and resulted in poor strength. Polymers that had large Rg by 
branching did not deteriorate sheet formation.

\subsubsection{Effect of larger molecular weight and higher degree of branching}

How larger molecular weight and higher degree of branching affected on improving sheet strength was evaluated using amphoteric PAM samples I, II and V (see Fig.6). I and II had the same kind of molecular structure and II had larger molecular weight than I. By increasing molecular weight, number of ionic groups in one polymer chain, which worked as retention sites, increased. As the $\mathrm{Rg}$ became larger, the chance of contacting pulp also increased. Therefore, sample II was less influenced by impurities, such as anionic trash that would hinder its retention, and its retention was improved. II and Vhad the same molecular weight and V was more branched than II . As the number of ionic groups in a molecular chain was the same, $\mathrm{V}$ that was highly branched had less $\mathrm{Rg}$ than II . So, ionic groups in $\mathrm{V}$ were more densely packed than II . The difference in the density of ionic groups could be measured by zeta-potential. Their zeta-potentials in sodium chloride solution on which concentration was $10 \mathrm{mM}$ were listed in Table 3. Though II and V had the same molecular weight and ionic property, $\mathrm{V}$ that was highly branched gave a larger zeta-potential. The higher density of ionic groups surely contributed to better retention of amphoteric PAM to pulp.

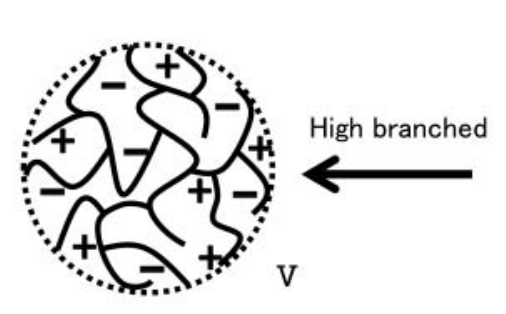

Increase ionic density

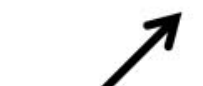

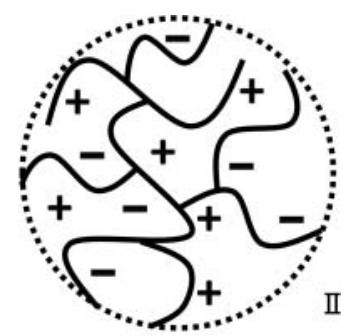

Increase ionic site

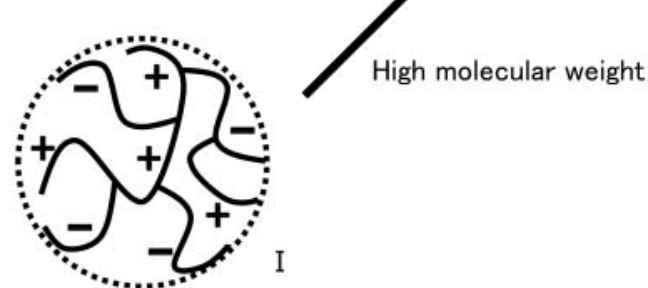

Fig. 6 Effect of molecular weight and structure change on the ionic character of amphoteric PAM

Table 3 Zeta-potential of amphoteric PAM

\begin{tabular}{cc}
\hline Sample & $\begin{array}{c}\text { Zeta-potential }^{\text {a) }} \\
(\mathrm{mV})\end{array}$ \\
\hline II & +5.9 \\
$\mathrm{~V}$ & +9.3 \\
\hline
\end{tabular}

${ }^{\text {a) }}$ Measured in $10 \mathrm{mM} \mathrm{NaCl}$ solution, at $\mathrm{pH} 3.5$

\subsubsection{Formation of poly-ionic complex}

It is known that amphoteric PAM that has anionic and cationic groups within itself is able to form poly-ionic complexes among them. It was expected that poly-ionic complex of amphoteric PAM would behave differently, dependent on its degree of branching like observed in zetapotential. Amphoteric PAM solutions of which electroconductivity was adjusted to $150 \mathrm{mS} / \mathrm{m}$ by adding $\mathrm{CaSO}_{4}$. $2 \mathrm{H}_{2} \mathrm{O}$ were prepared. Their light transmittance was measured as a function of $\mathrm{pH}$, which was shown in Fig. 7. In the ranges where light transmittance was low, amphoteric PAM formed poly-ionic complexes and its solution got milky. V that was highly branched did it in a wider range than II. The solutions were further adjusted to electroconductivity of $650 \mathrm{mS} / \mathrm{m}$ by adding $\mathrm{CaCl}_{2} \cdot 2 \mathrm{H}_{2} \mathrm{O}$. Then, II that was less branched could not form poly-ionic complex as electro-static force between ionic groups was shielded by the presence of inorganic salt abundant in the solution. On the other hand, V that was highly branched could form the complex even in the solution of high electro-conductivity. It was concluded that highly branched amphoteric PAM was less influenced with shielding effect by inorganic salt on its electro-static force as it had ionic groups in higher density.

When a lot of inorganic salt is present in water, packing ionic groups in high density by branching will increase effective charge of polymer and help form ionic complexes. Therefore, highly branched amphoteric PAM will work effectively to increase dry strength in a paper-making condition where electro-conductivity is high. The effect on dry strength with different electro-conductivities, 150, 350 and $550 \mathrm{mS} / \mathrm{m}$ respectively, which were controlled by $\mathrm{CaSO}_{4} \cdot 2 \mathrm{H}_{2} \mathrm{O}$ and $\mathrm{CaCl}_{2} \cdot 2 \mathrm{H}_{2} \mathrm{O}$, was determined with samples II and $\mathrm{V}$, and was summarized in Fig. 8. Their dosage was $0.5 \%$. Though sheet strengths were declined with in-

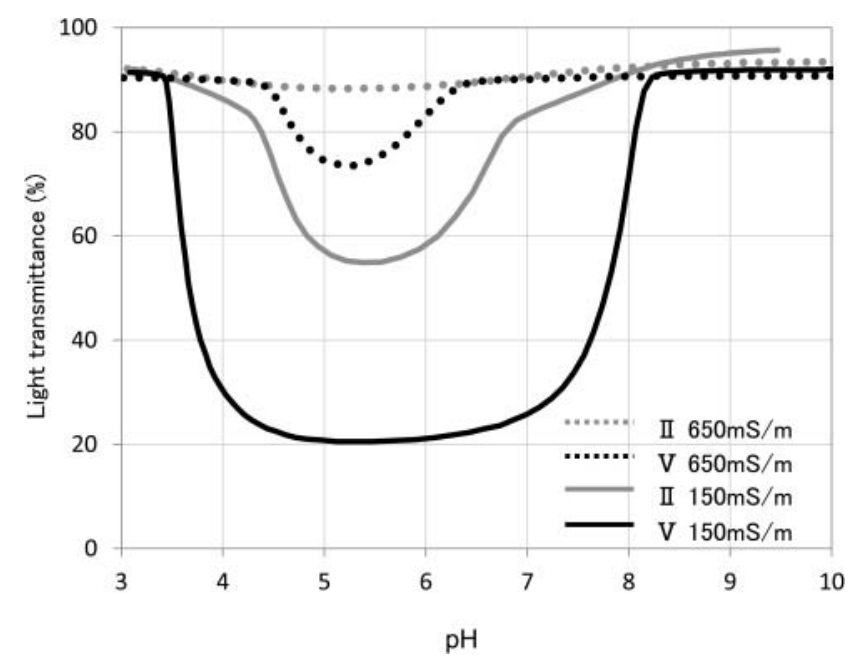

Fig. 7 Light transmittance change of amphoteric PAM solution as function of $\mathrm{pH}$ 


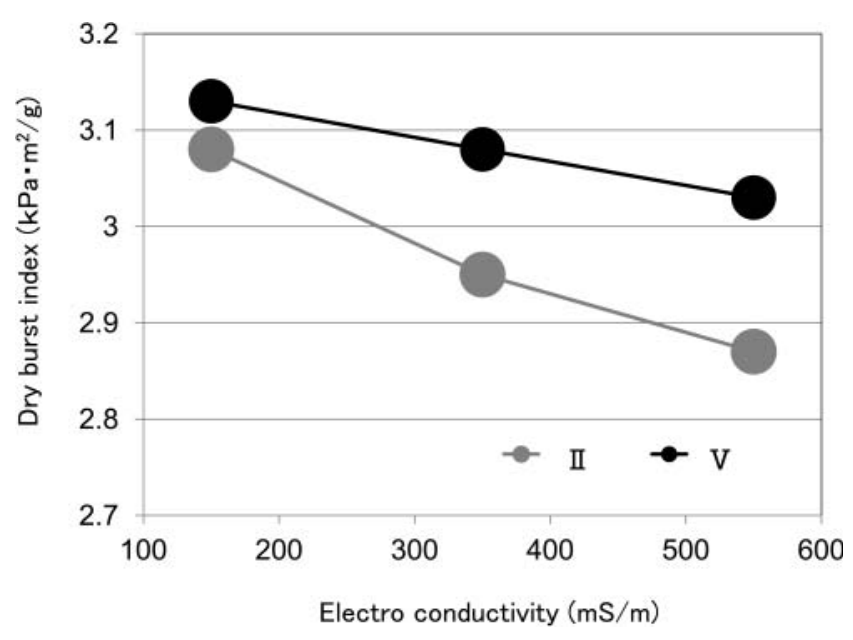

Fig. 8 Effect of electro-conductivity on paper strength

creasing electro-conductivity, their losses were far smaller in V than in II .

\section{Conclusion}

How the structure of amphoteric PAM affected on its dry strength was investigated. Several amphoteric PAMs were synthesized which contained the same amount of ionic monomers and were different in radius of gyration, molecular weight and degree of branching. By introducing branched structure, amphoteric PAM could be of large molecular weight and have large $\mathrm{Rg}$ without increasing its solution viscosity. By increasing the degree of branching, amphoteric PAM which had high molecular weight and also had large $\mathrm{Rg}$ (sampleVI) would be applicable in use though it was believed to be impossible.

It was found that by controlling amphoteric PAM's structure, its ability as dry strength resin could be improved. Our findings are summarized as below.

1) Increasing molecular weight with maintaining the same molecular structure which means to increase molecular weight as well as $\mathrm{Rg}$, number of retention sites (ionic groups) in one molecular chain will in- crease. As the $\mathrm{Rg}$ also gets larger, the retention of amphoteric PAM on pulp will improve. Improved retention results in better dry strength.

2) Increasing the degree of branching at the same molecular weight (higher branching)

The density of ionic groups in polymer chain will increase and its retention on pulp will be improved. Improved retention results in better dry strength. High density of ionic groups make polymer less influential to shielding effect by inorganic ions and help form poly-ionic complexes. As a result, it works in a papermaking condition in which electro-conductivity is relatively high.

3) Increasing branching and molecular weight at the same time

By the synergistic effect with 1) and 2), the best result will be obtained.

The environment in paper making will become less and less favorable to wet end chemicals, one of which is dry strength resin. We will do our best to supply chemicals of fine function applicable for future paper making.

\section{References}

1) W. F. Linke : Tappi 45326 (1962)

2) H. L. Needles, R. E. Whitfield : J. Polym. Sci. PartA 3 3543 (1965)

3) W. M. Kulicke, H. H. Hörl : Coll. Polym. Sci. 38133 (1959)

4) Toki et al. (Mitsui Toatsu Chem Inc.) : JP 3545473 (B 2)

5) M. Nakajima : JAPAN TAPPI Journal 52 (12) 1699 (1998)

6) T. Shimoyoshi, F. Chigira, O. Higashiura, S. Iida, M. Ishida : JAPAN TAPPI Journal 55 (11) 1555 (2001)

7) M. L. Huggins : J. Am. Chem. Soc. 642716 (1942)

8) H. Yamakawa : Modern Theory of Polymer Solutions, Harper \& Row, 1971, 47

(Manuscript accepted 9 June, 2012) 